(1) $O$ Observatori de

Bioètica i Dret

ISSN: 1886-5887

\section{Revista de Bioética y Derecho}

Publicación del Máster en Bioética y Derecho www.bioeticayderecho.ub.edu

ARTíCULO

\title{
Asedio compasivo: los vericuetos del cuidar $^{1}$
}

\author{
María CASAdo* \\ Ma JESÚs BuXó*
}

\begin{abstract}
${ }^{1}$ Este artículo resume las conclusiones de un trabajo más amplio llevado a cabo por las autoras por encargo de la Corte Suprema de México, a lo largo del primer trimestre de 2012, dentro del contexto de las relaciones entre género y bioética.

* Dra. María Casado. Catedrática de Universidad. Directora del Observatori de Bioètica i Dret y titular de la Cátedra UNESCO de Bioética de la Universitat de Barcelona. Creadora y directora del Máster en Bioética y Derecho de la Universitat de Barcelona. mariacasado@ub.edu

* Dra. Ma Jesús Buxó. Catedrática de Antropología Cultural. Investigadora del Observatori de Bioètica i Dret y miembro de la Cátedra UNESCO de la Universitat de Barcelona. Profesora del Máster en Bioética y Derecho de la Universitat de Barcelona. buxomj@ub.edu
\end{abstract}




\section{Índice}

El diagnóstico precoz de Alzheimer y otras demencias seniles

El periodo ventana

Cuidar versus Asediar

La banalidad del mal

Inquietudes finales

Bibliografía

\section{Resumen}

Es un hecho reiteradamente constatado que la población de nuestras sociedades está envejeciendo y se prevé que esta tendencia seguirá aumentando de forma exponencial en los próximos años. Este tramo de la población requiere y requerirá de atenciones muy especiales que imponen a los cuidadores una carga dura; también es sabido que dicha tarea recae generalmente sobre las mujeres de la familia, y por tanto debería hablarse con más propiedad de cuidadoras. Asociado al aumento de la media de edad, una de las enfermedades que más impacto ocasionan precisamente por los cuidados específicos que requiere y el largo lapso de tiempo con que cursa- es la enfermedad de Alzheimer que lleva camino de convertirse en uno de los más graves problemas de salud pública mundiales. Actualmente carece de cura y no se vislumbra que a corto-medio plazo se puedan conseguir terapias que hagan revertir la enfermedad, no obstante existen prometedores fármacos que se encaminan a enlentecer la evolución de los síntomas. Donde se han logrado mayores avances es en el diagnóstico precoz de la enfermedad y en este campo se están llevando a cabo grandes esfuerzos en investigación; pese a estos avances diagnósticos, la causa de la mayor parte de los casos de Alzheimer es desconocida, si bien hay acuerdo en que su desarrollo requiere la interacción de diversos factores -endógenos y exógenos- lo que la convierte en una enfermedad de etiología compleja y en la que existe un largo periodo ventana entre la detección de la enfermedad y la aparición de los síntomas. Este hecho nos ha llevado a detectar en este período la existencia de un problema bioético relevante ligado a los cuidados que es el núcleo central de este trabajo.

Palabras clave: vulnerabilidad, Alzheimer, diagnóstico precoz, autonomía, abuso, Derechos Humanos.

\section{Abstract}

Alzheimer's is on the way to becoming one of the world's most serious health care problems. Associated with the rising average age of the population, it is one of the diseases with the highest impact particularly on both persons affected by it, their close relatives and the health system and, in 
general, the whole of society. There is currently no cure for this disease and the speed of its development remains unknown although a long period of opportunity between detecting the disease and the onset of the first symptoms has been noticed. So the greatest efforts in research and discoveries have focused on detecting the disease at an early stage. This leads us to observe the existence of a major bioethical problem in this period linked to health and family care which concerns the autonomy, privacy and dignity of persons detected. Abuse can be committed at home, in care homes and hospitals, but how this is done in one place or the other differs, so additional variables to already established protocols regarding abuse in hospitals and Ethics Care Committees have to be considered, such as compassionate harassment.

Key words: vulnerability, Alzheimer, early diagnosis, autonomy, abuse, Human Rights. 


\section{El diagnóstico precoz de Alzheimer y otras demencias seniles}

La enfermedad de Alzheimer lleva camino de convertirse en uno de los más graves problemas de salud pública mundiales. Asociada al aumento de la media de edad en la población es una de las enfermedades que más impacto ocasionan en la persona que la padece, en la familia que la rodea, en el sistema sanitario entendido de forma amplia y, en general, en toda la sociedad. Actualmente carece de cura, aunque existen prometedores fármacos que se encaminan a enlentecer la evolución de los síntomas. Sin embargo, donde se han concentrado los esfuerzos en investigación y se han logrado mayores avances es en el diagnóstico precoz de la enfermedad. Pese a todo, es desconocida la causa de la mayor parte de los casos de Alzheimer así como el ritmo de su proceso de desarrollo; se constata que existe un largo periodo ventana entre la detección de la enfermedad y la aparición de los síntomas.

Este hecho nos ha lleva a observar en este período la existencia de un problema bioético relevante ligado a los cuidados que es el núcleo central de este trabajo aunque es sabido que son muchas las consideraciones que, en el marco de la Bioética, se presentan y debaten desde hace años a propósito del Alzheimer ${ }^{2}$. Algunas de ellas resultan ser problemas propios de la geriatría en general; otras se constituyen como cuestiones específicas que atañen a la autonomía, la intimidad y la dignidad de las personas que reciben un diagnóstico precoz, y que conlleva la puesta en marcha de la atención sanitaria y familiar.

Es un hecho que en el entorno asistencial y en el domicilio se pueden producir diversos tipos de conductas lesivas para aquellos a los que se cuida; de ahí que efectivamente, en los hospitales ya existan "protocolos de abusos" y desde los Comités de ética asistencial se propicie que el personal sanitario sea especialmente diligente en su detección y erradicación. En estos protocolos se analiza quienes son susceptibles de sufrir abusos, se establecen planes de actuación y se define qué se considera una persona vulnerable. La dificultad para detectarlos está condicionada por el propio anciano que no se atreve a manifestarlos si se producen en el entorno familiar -o tiene dificultades para expresarse- y también porque

\footnotetext{
${ }^{2}$ Hace más de diez años, desarrollamos un proyecto de investigación sobre las implicaciones bioéticas de la detección de genes asociados a la enfermedad de Alzheimer, financiado por el Plan Nacional de I+D del estado español, cuyo resultado nos permitió establecer pautas para enfocar los problemas aparejados al diagnóstico de esta enfermedad que, aun hoy, pueden ser valiosas como antecedentes; en especial para todo aquello que se refiera a la detección y evitación de abusos a quienes se hubiere detectado la enfermedad. Nuestro Proyecto de investigación recomendaba establecer medidas encaminadas a la garantía de una atención digna y no discriminatoria por razones de edad y pronóstico. Entre ellas, la implementación de los Comités de ética en las instituciones geriátricas y en la asistencia primaria, ya que la supuesta incompetencia del anciano facilitaba que en estos ámbitos se perpetuasen modelos paternalistas, sin tener suficientemente en cuenta los valores e intereses de cada persona y su dignidad específica.

Proyecto de Investigación PB-0987 "Derecho y Alzheimer: implicaciones jurídico políticas, éticas y sociales de la detección de genes asociados a la enfermedad de Alzheimer y otras demencias seniles", concedido por el Ministerio de Educación y Cultura y desarrollado por los miembros del Observatori de Bioètica i Dret del Parc Científic de la Universitat de Barcelona, investigadora principal del proyecto M. Casado. Los principales resultados de este trabajo fueron publicados en el libro El Alzheimer: problemas eticos y juridicos, coord. M. Casado, VV.AA., Ed.Tirant Lo Blanch, 2002.
} 
el personal sanitario suele estar poco entrenado para ello. Los abusos pueden perpetrarse en el domicilio familiar, en las residencias de ancianos y en el medio hospitalario, pero las formas en que se llevan a cabo en uno u otro lugar son distintos. Pueden ser de tipo físico, verbal y, aún más frecuentemente, de tipo emocional, abandono, infantilización, o de tipo financiero, entre otros. Para disminuirlos deben abordarse medidas de tratamiento para los casos en que ya se hayan producido -rompiendo el silencio, escuchando a las víctimas para ayudarles a recuperar la confianza y autoestima, determinando incluso si existe responsabilidad jurídica- y medidas sociales encaminadas a su prevención. En una sociedad centrada en la autonomía de las personas, estas circunstancias pueden parecer extremas, pero la realidad es que la realidad es que son frecuentes y muestran resultan frecuentes en ciertas situaciones la vulnerabilidad ${ }^{3}$ de los ancianos dependientes y con trastornos cognitivos, que requieren apoyo y vigilancia para que no se lesionen sus derechos ${ }^{4}$.

\section{El periodo ventana}

Actualmente, en lo que se refiere a las demencias seniles, los intereses de la investigación se orientan a conseguir diagnósticos precoces, aunque esto suponga investigar con un elevado número de personas sanas entre los que destacan los miembros jóvenes de las familias de los enfermos ${ }^{5}$. Quizás por tres razones, la más dura es relativa a que de momento es lo único o lo mejor que la investigación es capaz de conseguir, otra es que esto encaja con una lógica de la anticipación inescapable propia del pensamiento hipotético deductivo y, por último, que en la ideología cultural occidental tiene correlatos en la sabiduría popular del vale más prevenir que curar, y que hoy entra de pleno en la cultura de la juventud dominante. Nada nuevo como ideal si miramos la historia de la humanidad que siempre ha buscado fórmulas para conseguir la eterna juventud aunque actualmente la idea de parecer o mantenerse joven invade todos los estilos de vida, lo cual hace que la longevidad de la población preocupe y oriente investigaciones y tratamientos terapéuticos y regenerativos con el fin de mantener y perfeccionar el potencial corporal y, si es posible, demorar el envejecimiento.

En este escenario, el gran motor ideológico y económico que impulsa el sistema de salud y la definición de bienestar -sin dejar de lado los réditos que la cronicidad del reumatismo, el colesterol y las disfunciones vasculares aportan-, enfoca ahora una demencia degenerativa primaria, el Alzheimer. Tanto

\footnotetext{
${ }^{3}$ Véanse los comentarios al Artículo 8 de la Declaración Universal de Bioética y Derechos Humanos de la Unesco -Vulnerabilidad humana e integridad personal-: "Bioética, dignidade humana e vulnerabilidade: a Declaração universal de bioética e direitos humanos da Unesco desde uma perspectiva Latino-americana", Jussara de Azambuja Loch, Gabriel Chito Gauer y Joaquim Clotet PUCRS, así como "Vulnerabilidad: la metáfora de las capas" Florencia Luna, FLACSO; ambos en Casado, M. Sobre la dignidad y los principios: análisis de la declaración Universal de Bioética y Derechos Humanos de la Unesco. Navarra: Civitas, 2009.

${ }^{4}$ Véase "Sobre I'atenció a la gent gran dependent a Catalunya", Butlletí Oficial del Parlament de Catalunya no 17. 12 de febrero de 2004, www.sindicgreugescat.org.

${ }^{5}$ Véase, a modo de ejemplo, la página web de la Fundación Pascual Maragall www.fpmaragall.org y, muy específicamente, el "Estudio ALFA" allí auspiciado: www.alfaestudi.org.
} 
se ha popularizado en los medios de comunicación de toda índole que ha impactado en la opinión pública para exhibir casos ejemplarizantes y ha entrado de pleno en el acervo popular aludiéndose al mismo para disculpar un olvido o cualquier otra carencia asociada a la edad y la memoria.

La investigación del Alzheimer permite saber cada vez más sobre esta enfermedad y las disfunciones que se generan por la pérdida estructural de tejido cerebral y el deterioro cognitivo ${ }^{6}$ y es posible diagnosticarla en fases muy iniciales e incluso presintomáticas; por ello cada vez más personas para detectarla llevan a cabo análisis genéticos y clínicos a la primera señal de alarma o inclusive antes, temerosos de padecerla. El incremento en número de diagnosticados es notable: unos 500.000 en España según la Confederación española de familias de enfermos de Alzheimer y otras demencias, y la estimación de 1.200 .000 para el $2025^{7}$, cuya prospectiva mundial para el 2050 es de unos cien millones de personas ${ }^{8}$.

Son ingentes las investigaciones para conseguir tratamientos, y aunque en menor escala, también los estudios sobre la atención de este nuevo protagonista del envejecer. Sin embargo, el resultado que más rinde no son las terapias para curar o mejorar las condiciones de esta enfermedad, sino los progresos en el diagnóstico y la detección precoz. El diagnostico puede ser genético, con todas las implicaciones que ello conlleva; pero, además, puede llevarse a cabo mediante pruebas clínicas diversas -tales como TACs, PETs y otras pruebas- y se acompañan de test psicológicos complejos que someten a la persona en trance de ser diagnosticada a un elevado estrés y a inconvenientes sobre los que no suele ponerse atención inmersos en el proceso creciente de medicalización que todo diagnóstico conlleva pero que consideramos deberían ser cuidadosamente valorados antes de acometer su inicio.

Es interesante tener en cuenta que es posible detectar cambios significativos de la función cognitiva incluso 12 años antes del diagnóstico clínico -sintomático- de la enfermedad. El empeoramiento de la fluidez verbal semántica constituye un signo de declive cognitivo detectable entre los primeros síntomas inespecíficos de una enfermedad -EA prodrómica-, y precede a alteraciones que se pueden detectar diversos test que ponen de manifiesto las fases ya clínicas pero aun precoces de la enfermedad. Más adelante, entre 10 y 8 años antes de que se instauren definitivamente los síntomas claros de la enfermedad, se van produciendo cambios significativos en el pensamiento abstracto verbal y en la memoria visual inmediata. Los estudios señalan que "...las quejas subjetivas de empeoramiento cognitivo y los primeros síntomas en el estado de ánimo aparecen 7-8 años antes del diagnóstico clínico. Por último, 5 años antes del diagnóstico parecen existir cambios significativos en la capacidad de realización de algunas actividades funcionales complejas como el uso del teléfono, del transporte público o de las finanzas. El deterioro clínico significativo de la función cognitiva, emocional y funcional se produce unos 3 años antes

\footnotetext{
${ }^{6}$ El final del desarrollo de la enfermedad es de tal alcance que se la incluye entre las demencias, pero existe una larga fase previa de la enfermedad durante la cual se producen cambios en el cerebro -atribuibles a la enfermedad- sin que el sujeto que la padece presente síntomas o signos clínicos evidentes.

${ }^{7}$ Confederación española de de asociaciones de familiares de personas con Alzheimer y otras demencias, [ref. de 10 de abril de 2012] página web: www.ceafa.es.

${ }^{8}$ Khachaturian, Z. S., et al. (2009), Creating a transatlantic research enterprise for preventing Alzheimer's disease, Alzheimers Dement, 5(4), 361-366.
} 
del diagnóstico de la demencia"'. También existen evidencias de la disminución en el rendimiento de la memoria episódica lo cual hace su aparición entre 6 y 8 años antes del diagnóstico, y se puede constatar que el empeoramiento en el recuerdo diferido es el primer síntoma de declive cognitivo ${ }^{10}$. Así, para la detección precoz de los problemas de memoria asociados a la EA, es importante la utilización de diversos test de cognición y variables asociadas ${ }^{11}$ así como pruebas que permitan la evaluación de los distintos tipos de memoria ${ }^{12}$.

En este contexto, el Alzheimer nos coloca ante la evidencia de que la medicina curativa tiene límites y de que hay procesos patológicos que, aunque no puedan ser curados, sí deben ser tenidos en cuenta para que se pueda ofrecer al enfermo atención integral y la mayor calidad de vida posible. A nuestro entender, el diagnostico precoz hace avanzar el proceso de medicalización y adelantar el paso de convertir al ciudadano en paciente objeto de cuidados. Anticipación diagnóstica que, de ser hecha, debería estar precedida por un proceso de información, consentimiento y consejo, previo y especialmente cuidadoso para que garantizase que quienes se someten a estas pruebas precoces ${ }^{13}$, pudiendo aun decidir por sí, no resulten disminuidos no ya por la enfermedad -que indudablemente aparecerá cuando corresponda- sino por el propio procedimiento emprendido que en el devenir habitual y "natural" conlleva medicalización y claudicaciones.

En pro del diagnóstico precoz, algunos estudios afirman que los fármacos no curan, pero la intervención farmacológica en las fases iniciales puede modificar el curso o la "historia natural de la

\footnotetext{
${ }^{9}$ Véanse los trabajos de Blesa, R., M. Pujol, M. Aguilar, P. Santacruz, I. Bertran-Serra, G. Hernandez, J. M. Sol, and J. Pena-Casanova (2001), Clinical validity of the 'mini-mental state' for Spanish speaking communities, Neuropsychologia, 39 (11), 1150-1157.

${ }^{10}$ Backman, L., S. Jones, A. K. Berger, E. J. Laukka, and B. J. Small (2005), Cognitive impairment in preclinical Alzheimer's disease: a meta-analysis, Neuropsychology, 19 (4), 520-531, un meta-análisis sobre las alteraciones cognitivas en la etapa prodrómica de la enfermedad.

${ }^{11}$ Ejemplo de los test a que nos referimos son: Clinical Dementia Rating, que permite evaluar clínicamente memoria, orientación, razonamiento, solución de problemas, actividades de la vida diaria, aficiones y cuidado personal. El Mini-Mental state Examination, que consiste en una evaluación breve de las capacidades cognitivas mediante preguntas sobre orientación temporal y espacial, registro mnésico, atención, cálculo, recuerdo, lenguaje y praxis. El Free and Cued Selective Reminding, que permite valorar la capacidad de la memoria verbal tras un procedimiento de aprendizaje controlado. Y el Trail Making Test, que evalúa procesos ejecutivos simples, como la atención selectiva y la secuenciación visomotora, así como procesos complejos, como la flexibilidad cognitiva.

${ }^{12}$ La memoria semántica se refiere al archivo general de conocimiento conceptual y fáctico, no relacionado con ninguna memoria en particular, que una persona posee; muestra el conocimiento del mundo, de las personas y de las cosas y su significado. Es un sistema distinto del de la memoria episódica y, de hecho, se puede perder memoria de acontecimientos y mantener la memoria de conceptos. La memoria episódica es el sistema de memoria que se utiliza para recordar experiencias personales enmarcadas en el propio contexto, como lo que se hizo el día anterior.

${ }^{13}$ Nótese que tales diagnósticos precoces a veces pretenden encontrar meramente factores de riesgo, lo que, en enfermedades de etiología tan compleja, equivale a "buscar una aguja en un pajar" pero conllevan necesariamente que el diagnosticado entre en la cadena del sistema médico.
} 
enfermedad", y, en concreto, con la entrada de fármacos específicos ${ }^{14}$ se obtienen beneficios sintomáticos y paliativos sobre la cognición y la actividad funcional, lo cual permite retrasar síntomas y conseguir un deterioro cognitivo menor que los no tratados. (Boada, 2002 y 2004). En el ámbito de la estimulación cognitiva y la asociación con actividades de ocio -como leer, escribir, participar en grupos, jugar, tocar instrumentos, crucigramas,...- se afirma conseguir una mejoría en la capacidad intelectual, autonomía y bienestar siempre y cuando sean aplicados desde el inicio de la enfermedad; en particular por la dificultad de integrar estas terapias con posterioridad. Extensivamente, estas ventajas y beneficios en mantener la autonomía de la persona el mayor tiempo posible y mitigar la dependencia, redundan en beneficio del núcleo cuidador que hace que la carga del cuidar sea más llevadera (Boada y Tárraga, 2004).

Estos mismos informes, no obstante, advierten que faltan más estudios y datos comparativos para discutir el beneficio del tratamiento farmacológico en la activación de las neuronas así como en las terapias de aprendizaje de habilidades y la estimulación cognitiva y así conseguir una mayor o menor mejoría transitoria. Señalan, asimismo, la conveniencia de refinar las metodologías de medición de los datos especialmente en la evaluación de la implementación de las técnicas y actuaciones y con ello demostrar el valor potencial de la rehabilitación cognitiva -y otros métodos psicosociales -como coadyuvante del tratamiento farmacológico. Y, en esta dificultad contribuye el hecho que no hay dos enfermos de Alzheimer idénticos, lo cual obliga a tener en cuenta las variaciones individuales de la persona, sus genes y su educación, su carácter y personalidad, sus traumas y frustraciones, sus logros y vivencias, sus amores y desamores, su entorno familiar, laboral y social. De no tener en cuenta todo esto, y si las tareas de estimulación son inadecuadas, se pueden producir crisis de "desconfianza y reacciones de rechazo y frustración" (Boada, idem. 39).

Sin duda, en este ámbito de la atención se reconoce que hay que elaborar nuevos modelos de actuación, de ahí que se desarrollen nuevas especialidades en salud pública, así como se impulsen fundaciones y asociaciones que realizan grandes esfuerzos por clarificar las bases biomédicas y culturales de la enfermedad así como identificar sus necesidades y problemas. Atender y cuidar constituyen bondades cuyo correlato bioético en términos de beneficencia se sustentan en una ética de la justicia y la imparcialidad en la atención del sistema sanitario y en una ética del cuidar cuyo referente es la sensibilidad moral natural asociada a las virtudes de lo que se define canónicamente como femenino y maternal.

Y es precisamente aludiendo a esas bondades, que consideramos que el diagnóstico precoz entra en una zona de grises y de límites imprecisos que requieren una reflexión añadida por la aparición de fenómenos de carácter negativo relativos a un doble filo del cuidar que puede conducir a la vulneración de derechos.

En el intervalo, entre la detección de la enfermedad -aun prácticamente asintomática- y su manifestación definitiva, el diagnóstico infausto promueve la aplicación de protocolos de actuación que aunque entendidos como mecanismos de prevención tan pronto se reconocen los primeros síntomaspueden tener efectos perjudiciales en el bienestar del afectado. Entrar en la atención protocolizada del

\footnotetext{
${ }^{14}$ Los IACE son fármacos específicos, considerados sintomáticos y paliativos, no curan pero algunos autores indican que pueden modificar el curso natural de la enfermedad (Boada, 2004).
} 
sistema sanitaria implica seguir unos parámetros cuya estandarizaron no tiene en cuenta la complejidad que se genera en las actividades, además, de los conflictos en el sistema familiar (Buxó, 2002), ni tampoco los vericuetos en la reelaboración de la identidad del diagnosticado entre recursos propios e imposiciones ajenas. Poco se sabe sobre la actividad de las neuronas y los sentimientos sometidos al stress de la información del diagnóstico precoz y que pueden ser los que inducen a las reacciones de frustración, apatía, aislamiento, irritabilidad, ansiedad y depresión. Y todavía menos de la etnografía cotidiana de los diagnosticados que pasan a ser sujetos pacientes de un sistema de restricciones sanitarias y familiares.

Paradójicamente, esa anticipación del diagnóstico que parece aportar ventajas al tratamiento de esta enfermedad progresiva, también produce desventajas pues, una vez advertida e informada, la persona y su espacio vital quedan reclasificados en el sentido foucaultiano de biopolitizar su cuerpo y su mente. A modo de inciso quedaría en el aire la pertinencia de este diagnóstico precoz, qué calidad de vida tendría la persona que no supiera de su estado, y cuan distinto sería su bienestar en otras condiciones de vida. Podría pensarse en la ruralidad de un pueblo donde la percepción de la disminución se nota menos debido a la combinatoria familia-vecinos, formas laborales y sistema de valores en que priva el respeto a la ancianidad sin importar los olvidos, la lentitud y otras incapacidades propias de la edad.

No es de extrañar, pues, que la anticipación agudice el sufrimiento del diagnosticado al quedar sometida su conciencia a la irreversibilidad del proceso, la imprecisión de la temporalidad y a los vericuetos de una identidad que cada vez más esta referenciada en los demás. Y en ese intervalo es donde se amplifica la vulnerabilidad que damos en denominar asedio compasivo.

\section{Cuidar versus Asediar}

En pro de una sociedad que busca asegurar el confort del individuo, de su salud como un signo de logro, bienestar y perfección, el diagnóstico precoz se entiende que contribuye a garantizar ese ideal. No solo se inicia el tratamiento terapéutico sino que se aporta una información de la cual es dueño el diagnosticado y que -como se ha dicho- le permite ejercer su autonomía antes de la perdida de la personalidad, para arreglar sus papeles y expresar sus voluntades respecto a cómo quiere que sea su tratamiento y final. Sin embargo, no parece tenerse en cuenta que, una vez se diagnostica la enfermedad de Alzheimer y se informa al enfermo y a la familia, empieza un periodo anómalo que afecta la identidad del diagnosticado doblemente presionado porque se instaura un proceso irreversible y entra en una categoría que, por incipiente que sea su condición, se enmarca en el sistema clasificatorio de las demencias neurodegenerativas. Así pasa a ser una entidad marcada por una redefinición medicalizada de su cuerpo y mente, que no solo conmueve o perturba las conductas de su entorno familiar sino que, socialmente, inicia el trayecto de las personas discapacitadas.

Es, pues, de interés bioético atender esta fase de anticipación donde la vulnerabilidad potencial del diagnosticado es incremental por dos razones: una, el peso de la movilización de todos los agentes de la atención y el cuidado que disponen de tratamientos, protocolos, consejos, recomendaciones sobre cómo actuar con el ya paciente quien ve transformados sus estilos de vida por la organización de los cuidados insertos en los quehaceres cotidianos. Y, otra, la presión a dar un salto cualitativo en la dirección de 
elaborar una nueva realidad desde el individuo -que es aún- hacia una consciencia distinta de si mismo, cuya identidad social está pasando a ser una entidad a ser tratada y cuidada ${ }^{15}$.

Desde siempre se ha reconocido que la atención sanitaria tenía que complementarse con el cuidado en el ámbito familiar en todas las enfermedades, con mayor acento si cabe en las discapacidades de larga duración y en el caso que nos preocupa aquellas de carácter neurodegenerativo. En el ámbito sanitario, el concepto de atención sirve para poner matices al cuidar en el sentido de objetivar lo que se siente, lo que la otra persona espera y las exigencias del guión terapéutico en cuanto a obligaciones y prioridades. Se entiende que los centros hospitalarios tienen que "atender", es la atención lo que se requiere y no la implicación afectiva del cuidador, sea hombre o mujer. Esto contrasta con el cuidado familiar en el que las mujeres de la familia, sea la esposa, la hija, la hermana o los parientes femeninos más próximos, o el servicio doméstico, son los que han de responsabilizarse del enfermo. De esa implicación familiar se reconocen dificultades y problemas que han servido para analizar la crisis familiar o incluso definir al cuidador como víctima-; de ahí derivan recomendaciones y aprendizajes para beneficiar el entorno cuidador, animarle en el proceso e incluso prepararlo para ser "maestro del reposo" (Tárraga, 2004). En definitiva, antes y ahora se han elaborado fórmulas para que la enfermedad se viva como algo aceptable y manejable, en lugar de ser una losa para la familia (Opinión Quiral, 21, 2011). Las asociaciones de pacientes, CEAFA, FEP ${ }^{16}$, elaboran guías para orientar a los medios de comunicación sobre como divulgar la enfermedad y los avances curativos, evitando las falsas expectativas; asimismo, consideran que estas noticias dedican poco espacio al entorno familiar en tanto que personas afectadas que necesitan respuestas y soluciones.

Si los cuidadores tienen, pues, el beneficio de este reconocimiento y apoyo, no parece que estas fórmulas contribuyan de igual modo al bienestar de los diagnosticados. En los trabajos sobre Alzheimer se dice que el diagnosticado cierra un periodo y se recomienda transformar su proyecto vital en tiempo de ocio y tranquilidad, siendo derivado hacia una suerte de jubilación en la que va notando -o se le hace notar- la pérdida de sus habilidades, la memoria y la auto ejecución. En las pruebas que acompañan el diagnóstico inicial - que se realizan para evaluar los trastornos cognitivos y psicoafectivos-, el paciente potencial se ve sometido a tests de abstracción y ejecución con dibujos, cálculos y escritura, cuya inmediatez y expectativas de aprobación, agudizan su sentido de merma de capacidades. Es cierto que se dan toda suerte de recomendaciones a los evaluadores con el fin de evitar la sensación de fracaso y la pérdida de autoestima, animar a esforzarse sin exigencia, y no interferir en aquellas tareas que los diagnosticados todavía son capaces de realizar por sí mismos.

La etnografía del entorno sanitario y familiar pone en evidencia que los cuidadores ante cualquier señal o detalle de limitación inician el proceso afectuoso de suplir y dependizar, lo que se convierte en una

15 Boff L. Saber cuidar: a ética do humano. 2007. www.dhnet.org.br/direitos/militantes/boff/boff etica humana.html.

Asimismo, Schwancke CHA, Cruz IBM. "Ética do cuidado na sociedade que envelhece: contribuição ao debate". In: Clotet J, Feijó AGS, Oliveira MG. (Org.) Bioética: uma visão panorâmica. Porto Alegre: EDIPUCRS, 2005.

${ }^{16}$ CEAFA, Confederación española de familiares de enfermos de Alzheimer y otras demencias.

FEP, Federación Española de Parkinson. 
manera de hacerles notar lo que eran y lo que queda de ellos. Animarles a no lamentar lo perdido, como técnica de apoyo, es otra forma equívoca de hacerles olvidar lo que fueron, pues son justamente esos recuerdos los que les dan alegría, a la vez que son puntos de referencia en la reactivación de otras acciones. Así, ante cualquier olvido saltan las alarmas de su nueva condición, y sea por apoyo o impaciencia, se tiende a acabar sus frases, se formulan sus preguntas y se termina diciendo aquello que se supone iba a decir el diagnosticado. Ante cualquier vacilación, se insinúan u organizan nuevos órdenes en el espacio y en el aseo personal, se interviene amablemente en sus decisiones, por no mencionar aspectos más oscuros relativos a la economía familiar, la herencia y que entran de forma subrepticia en los detalles afectuosos, el tono de los comentarios y la frecuencia de las discusiones. En casa, el afectado queda pronto expuesto a la intromisión de las conductas familiares que, aun si son con toda la buena voluntad del mundo, anticipan síntomas y favorecen entornos donde reinan en pro de la aceptabilidad y el manejo, los actos de dependencia y disminución. Es frecuente que el diagnosticado se vea obligado a elaborar su identidad con mecanismos defensivos de aislamiento y un cierto escapismo que se expresa también difiriendo decisiones y actividades, incluso con manifestaciones irregulares de agradecimiento compulsivo, irritabilidad y despego. $Y$ todo ello es interpretado por los cuidadores como parte de la enfermedad, cuando en realidad son conductas que derivan en buena medida del acoso compasivo al que es sometido.

En definitiva, mientras por una parte se cumple institucionalmente con la prevención y los derechos en salud del individuo, por otra el diagnóstico precoz conmociona la vida del nuevo paciente al que se le inflige un "asedio compasivo" donde -en nombre del afecto y el servicio- se mezclan indignamente toda suerte de controles. Expresiones y prácticas que se entienden por parte del cuidador o cuidadoras dedicación que, en general, recae en las mujeres de la familia- como desvelo, dedicación y mimos y se reciben, ambiguamente, por parte de la persona cuidada como "afecto invasivo" que en ocasiones invalida el proceso de asumir la enfermedad, elaborar la identidad y reordenar el espacio vital.

Y es, justamente, en el período del diagnóstico precoz donde mayor relieve alcanza el asedio compasivo, pues se refuerzan todos los dispositivos emocionales del círculo intimo que, no sintiendo el cuidar como una obligación sino receptividad ante el destino cruel, desatan la empatía, el ponerse en lugar del otro, sentir con el otro, ver las cosas desde su punto de vista, y llevada al extremo la identificación, hacer todo y más por el otro.

En términos bioéticos, este trato de confianza y solidaridad quedaría clasificado como beneficencia ya que no hay maleficencia en el sentido de una desatención que produzca directa o indirectamente marginación, vulnerabilidad, malos tratos, abandonos, sea por escasez de recursos y servicios como por conflictos emocionales y desintegración socio-familiar. Sin embargo, puede llegar a ser maleficencia y afectar derechos fundamentales en cuanto a la intimidad y la autonomía pues se trata de un cuidado en exceso o invasivo que hace que los miembros de la familia suplanten y se apropien anticipada y progresivamente de la voluntad y la capacidad de decisión de la persona diagnosticada; especialmente cuando se notan vacilaciones asociables a la pérdida de memoria y la auto ejecución.

No es de extrañar, pues, que con estas actitudes de la atención y el cuidado se induzca a ejercer, incluso a justificar, el acoso en nombre del bienestar. Complementariamente, tampoco es raro que, con toda esa buena voluntad, el diagnosticado tienda a hacerse el distraído o usar estrategias que le hagan inmune a la intromisión de estas presiones y fuerzas externas. Irritarse, hacerse el ausente y retirarse a su 
mundo interior son manifestaciones que a la vez perjudican su imagen retroalimentado el asedio compasivo.

De poco serviría concluir algo tan obvio como que el diagnosticado precoz de Alzheimer requiere un "apoyo inteligente" que facilite o contribuya a su bienestar. En esta fase o intervalo, sería conveniente hacer un seguimiento de las transacciones morales que se mueven detrás de la escenificación del cuidar. Así, el apoyo inteligente implica soslayar el principio del doble efecto y la banalidad del mal, dos problemas bioéticos de primer nivel.

Por una parte, es preciso darse cuenta que los agentes del sistema sanitario y familiar "bien intencionados" aplican el principio del doble efecto cuando se permiten en el curso de una acción causar un perjuicio para producir un buen fin que no es posible conseguir sin dañar y, además, considerar raramente la proporcionalidad. En el caso que nos ocupa, no hay que olvidar que se trata de un diagnostico precoz y sin terapia aparejada; más aún, el diagnostico de una enfermedad irreversible y que puede ser detectada cuando aún es totalmente asintomática. Este conjunto de graves circunstancias nos enfrenta a las cuestiones de si es o no procedente revelar el infausto diagnóstico a los hipotéticos afectados y como se ha de llevar a cabo la necesaria labor de consejo y orientación ${ }^{17}$.

Por otra parte, habría que entender los aspectos contradictorios del "don" que subyacen al cuidar; sin lo cual es fácil caer en la "banalidad del mal".

\section{La banalidad del mal}

El don que subyace el cuidar supone una de las formas más arcaicas de intercambio interpersonal en las que la generosidad y la gratuidad son valores que se substancian en el dar, recibir y devolver. Sin embargo, no existen comportamientos desinteresados ni actos gratuitos, más bien toda acción se plantea, de un modo u otro, para alcanzar algún tipo de beneficio, sea el cielo, el agradecimiento, la autosatisfacción de estar actuando correctamente con uno mismo y con los demás, el reconocimiento público o, también, el sentido de pertenencia a una organización y sus poderes, sea el sistema biomédico o la sagrada familia. Implica, además, una relación ambigua o confusa entre el dar y el devolver, que no es de reciprocidad sino de obligación. Madrid $(2001,173)$ advierte sobre las obligaciones que genera el don obligaciones de devolución- derivando en un mecanismo de distribución de poder social puesto que más se da, más poder se tiene, así "la diferencia de poder entre los individuos es proporcional a los desequilibrios

${ }^{17}$ En este sentido, las Recomendaciones del Consejo de Europa sobre cribados genéticos con fines sanitarios y sobre protección de datos médicos, establecen que no debe ser lícito exigir pruebas genéticas para la realización de seguros ni para los contratos laborales y, en general, los países europeos sostienen esta opinión. En nuestro ordenamiento jurídico, el marco general lo establecen lo dispuesto por el Convenio de Derechos Humanos y Biomedicina, cuyo artículo 12 sólo permite el uso de la información genética con fines médicos o de investigación médica, la Ley Orgánica 15/1999, de 13 de diciembre, de Protección de Datos de Carácter Personal, que se encamina a proteger la intimidad y consagra la llamada autodeterminación informática, así como la Ley 14/2007, de 3 de julio, de Investigación biomédica cuyo Tit. V regula los análisis genéticos. 
de la reciprocidad entre estos". Aunque lo más preocupante es que casi nunca se pone en evidencia la labor negativa que se ejerce sobre el receptor pues, según Todorov $(1995,152)$, el individuo caritativo obtiene el reconocimiento de realizar un acto considerado moral pero al mismo tiempo hace como si el otro solo tuviera necesidad de recibir pero no de dar, una actitud de sentido único que promueve la desproporción o el "dar sin medida" lo cual coloca a los beneficiarios en desventaja y sumisión.

Y ahí está el núcleo del asedio compasivo, más se da y más desproporcionado es el cuidado, mayor es el poder de decisión que menoscaba la del receptor sumido en la obligación y el agradecimiento. Es importante reconocer que en el dar y en el cuidar aunque se piense en el bien del otro, resulta un bien para uno mismo que generalmente pasa desapercibido para quien cuida y para el medio, pero que no por eso es menos real ni menos invasivo. $Y$ no solo eso, sino que se establecen relaciones de dependencia que tienden a generar en el receptor sentimientos de deuda, aunque sean automatismos convencionales, pero que sin duda retroalimentan la continuidad y la profusión del cuidar. Ciertamente, nada nuevo bajo el sol, pues parece que hayamos olvidado las palabras de Aristóteles (Ética a Nicómaco, 1995, L. IX, Cap VII): "el resultado de la acción es hermoso para el bienhechor de modo que complace a la persona que da, mientras que el servicio del bienhechor no es hermoso para la persona que lo recibe, sino, en todo caso, útil, y esto es menos que grato y amable". Y también Nietzsche $(1990,76)$ nos advierte en la consideración de la voluntad de poder del ser humano que ésta convertía los actos más bellos y hermosos en actos interesados: "...torpe ardid consistente en formarse una idea corregida de la persona a la que se trata de ayudar; pensando que esta merece ayuda, que anhela precisamente su ayuda y que se mostrara profundamente agradecida, adicta y sumisa a ellos por toda su ayuda... con esta fantasía disponen de los necesitados como propiedad suya... los encontramos celosos cuando nos cruzamos con ellos o nos adelantamos a ellos"..

Olvidar estas lecciones básicas en la consideración de una ética del cuidar sólo nos lleva a pensar en la banalidad del mal entendido como provocar el mal sin que haya voluntad de hacerlo. En la descripción de este concepto, Arendt (2011) señala que puede dar lugar a una auténtica controversia ya que cuando habla de la banalidad del mal se limita a señalar un fenómeno caracterizado por la irreflexión y la normalidad. Un mal que no busca hacerse y que es resultado de la inadvertencia, que no estupidez. Y por ello de una predisposición a actuar con un esmero exagerado en un marco de instituciones jurídicas y morales cuyo acatamiento casi impide saber que se realizan actos de maldad.

No es una comparación sino una reflexión, simplemente incomoda, sobre los valores intrínsecos de dos sistemas de poder y autoridad, el sanitario y el familiar, que proceden de tradiciones no cuestionadas, basadas en los avances tecno-científicos y la veneración sagrada a los vínculos familiares. Ambos y en conjunción operan como rigurosas sucursales del orden y la felicidad entrometiéndose en la intimidad del diagnosticado, actuando ajenos a su voluntad personal y reduciendo las oportunidades para que use sus propios recursos. Sin duda, es una aplicación conceptual poco grata asociar la banalidad del mal con conductas regladas y basadas en la afectividad pero, aun reconociendo la exageración, hay un doble filo en el cuidar que, si no se revisa, puede conducir al asedio compasivo. No porque haya mala intención ni sadismo, sino por pura y simple normalidad e irreflexión. 


\section{Inquietudes finales}

Si no fuera por el diagnóstico precoz, seguramente no habríamos cuestionado el cuidar con la misma intensidad crítica, de ahí que las consideraciones finales se dirijan al origen del problema. El reparo de fondo se asienta en la realización de cierto tipo de amplios estudios preclínicos -presintomáticos- que se encaminan a conseguir un diagnóstico cada vez más precoz de enfermedades sin cura y de etiología compleja $^{18}$. Consideramos que los recursos y esfuerzos de la investigación deberían destinarse prioritariamente a la terapia de la enfermedad no a detectar -masivamente y cuanto antes- factores de riesgo multifactoriales y posibles futuros enfermos de Alzheimer ya que se trata de una cuestión muy sensible por sus profundas implicaciones éticas, el número de afectados -actual y futuro- y la enorme carga simbólica de esta enfermedad, que hace que su diagnóstico lleve aparejada una condena sin remedio y que los diagnosticados pasen a ser pacientes de hecho $\mathrm{y}$, al ser vistos como vulnerables, vean recortados sus derechos. Es necesario señalar que no siempre etiquetar a alguien como vulnerable lleva aparejado el esfuerzo de tratar de respetar su autonomía en todo aquello que la tiene e intentar completarla en aquello que le falte, sino que pura y simplemente se le sustituye en la toma de decisiones; esto no ocurre solo con los ancianos sino también con los menores o con cualquier otro colectivo en los que la etiqueta de vulnerabilidad acaba implicando discriminación y pérdida de derechos, no sólo protección. Así, se acorta su autonomía y se les somete a un asedio compasivo por parte por parte del sistema sanitario -que lo erige como un colectivo más a medicalizar y en una nueva fuente de intereses y de trasiego económico- y del sistema familiar -por extralimitación conmiserativa.

Nuestra inquietud bioética es, pues, profunda y previa ¿se debe aceptar que se dediquen tales esfuerzos a este tipo de estudios pre-sintomáticos y sin terapia disponible? Ciertamente es bien sabida la capacidad de presión que tienen ciertas entidades -las fundaciones dedicadas a llevar a cabo "obras sociales", por ejemplo- sobre la opinión pública. El apoyo de los promotores y el renombre de algunos de los investigadores que participan e impulsan estos proyectos a menudo salva carencias, e incluso predispone a la sociedad a favor - 0 , al menos, a no cuestionar algo que se hace a "fin de bien"- cuando en realidad ese apoyo tal vez sería más necesario para otras cosas que no generasen falsas expectativas en pacientes, familiares y ciudadanos en general. Este tipo de iniciativas y el apoyo mediático que las acompaña -la mera publicidad de ciertos estudios prospectivos que se llevan a cabo- condicionan a los ciudadanos a medicalizar su vida "por si acaso", a someterse a diagnósticos precoces y test imposibles de

\footnotetext{
${ }^{18}$ Este reparo ya ha sido también puesto de manifiesto por diversas personas e incluso comisiones de ética; por ejemplo en el Comité de Bioética de Cataluña, en su sesión de junio de 2012, se elaboró un informe que cuenta con un voto particular en este sentido, encabezado una de las coautoras de este trabajo, cuyos lineamientos se recogen en los siguientes párrafos. Véase el informe de "Comitè de Bioètica de Catalunya" de la reunión plenaria del 13 de junio de 2012, a propósito del protocolo del proyecto de investigación "Estudio Cohorte para la identificación precoz de marcadores en familiares cognitivamente sanos de pacientes con enfermedad de Alzheimer", que impulsa la Fundació Pasqual Maragall y el voto particular firmado por Maria Casado, Jose Maria Mena, Montserrat Busquets, Lluis Cabre y Francesc Jose Maria, con la adhesión de Virtudes Pacheco.
} 
responder por ningún ser humano normal sometido a tal presión... y luego se extrapolan resultados de forma que se ve obligado a tomar medidas y remedios proporcionados, obviamente, por la industria.

\section{Bibliografía}

- Amieva, H., M. Le Goff, X. Millet, J. M. Orgogozo, K. Peres, P. Barberger-Gateau, H. Jacqmin-Gadda, and J. F. Dartigues, Prodromal Alzheimer's disease: successive emergence of the clinical symptoms, Ann Neurol, 64 (5), 492-498, 2008.

- Anscombe, G.E.M. Modern Moral Philosophy, Philosophy, vol. 33, 124, 1-19, 1958. www.jstor.org.

- Aristóteles, Ética a Nicómaco, Madrid, Gredos, 1995.

- Arendt, H. Eichman en Jerusalén, Barcelona, DeBolsillo, 2011.

- Azambuja Loch, J., G. Chito Gauer y J. Clotet, Vulnerabilidad humana e integridad personal: Bioética, dignidade humana e vulnerabilidade: a Declaração universal de bioética e direitos humanos da Unesco desde uma perspectiva Latino-americana. En: M. Casado, Sobre la dignidad y los principios: análisis de la declaración Universal de Bioética y Derechos Humanos de la Unesco. Navarra: Civitas, 2009.

- Backman, L., S. Jones, A. K. Berger, E. J. Laukka, and B. J. Small Cognitive impairment in preclinical Alzheimer's disease: a meta-analysis, Neuropsychology, 19 (4), 520-531, 2005.

- Blesa, R., M. Pujol, M. Aguilar, P. Santacruz, I. Bertran-Serra, G. Hernandez, J. M. Sol, and J. PenaCasanova (2001), Clinical validity of the 'mini-mental state' for Spanish speaking communities, Neuropsychologia, 39(11), 1150-1157, 2001.

- Boff, L. Saber cuidar: a ética do humano. 2007. www.dhnet.org.br/direitos/militantes/boff/boff eticahumana.html.

- Butlletí Oficial del Parlament de Catalunya, Sobre I'atenció a la gent gran dependent a Catalunya, 17, 2004, www.sindicgreugescat.org.

- Buxó Rey, M.J. La familia, objecte i subjecte de salut mental. Barcelona, Quaderns de Salut Mental, 1, 46-50, 2002.

- Boada, M. y Tárraga, LL. Alzheimer: La memoria esta en los besos. Barcelona, Ediciones Mayo, 2002.

- Casado, M. (ed.), El Alzheimer: Problemas éticos y jurídicos, Valencia, Tirant lo Blanc, 2002.

- Casado, M. Cuestiones bioéticas en torno al envejecimiento, Revista BIOÉTICA, Brasil, vol. 19, 3, 697712, 2011.

- Gilligan, C., In a different voice. Psychological Theory and Women's Development, Cambridge, Harvard University Press, 1982.

- La moral y la teoría: psicología del desarrollo femenino, México, F.C.E., 1994. 
- Khachaturian, Z. S., et al., Creating a transatlantic research enterprise for preventing Alzheimer's disease, Alzheimers Dement, 5(4), 361-366, 2009.

- Lèvinas, E. Entre nosotros: ensayos para pensar en otros. Valencia, Pre-textos. 1993.

- Madrid, A. La institución del voluntariado, Madrid, Trotta, 2001.

- Luna, F. Vulnerabilidad: la metáfora de las capas. En: M. Casado Sobre la dignidad y los principios: análisis de la declaración Universal de Bioética y Derechos Humanos de la Unesco. Navarra: Civitas, 2009.

- Minayo, MCS. Violência contra idosos: relevância para um velho problema. Cad. Saúde Pública, 19(3): 783-91, 2003.

- McKhann, G., D. Drachman, M. Folstein, R. Katzman, D Price, E. M. and Stadlan,

- Clinical diagnosis of Alzheimer's disease: report of the NINCDS-ADRDA Work Group under the auspices of Department of Health and Human Services Task Force on Alzheimer's Disease, Neurology, 34(7), 939-944, 1984.

- Nietzsche, F. Más allá del bien y del mal, Madrid, Alianza, 1990,

- Noddings, N. Caring, a feminine approach to ethics and moral educations, Berkeley, University of California Press, 1984 .

- Opinión Quiral, Enfermedad de Alzheimer, diagnóstico precoz, 32.1, 2011.

- Schwancke, CHA. IBM. Cruz, Ética do cuidado na sociedade que envelhece: contribuição ao debate. En: J. Clotet, AGS. Feijó, M.G. Oliveira (eds.) Bioética: uma visão panorâmica. Porto Alegre: EDIPUCRS, 2005.

- Tárraga, LI. y Boada, M. (eds.) Cuadernos de repaso, Fundación Ace, Barcelona, Editorial Glosa, 2004.

- Todorov, T. La vida en común, Madrid, Taurus, 1995.

Fecha de recepción: 12 de julio de 2012

Fecha de aceptación: 29 de septiembre de 2012 